\title{
The potential effects of climate change on malaria transmission in Africa using bias-corrected regionalised climate projections and a simple malaria seasonality model
}

\author{
Volker Ermert • Andreas H. Fink • Heiko Paeth
}

Received: 22 March 2012 / Accepted: 16 July 2013 / Published online: 6 August 2013

(C) The Author(s) 2013. This article is published with open access at Springerlink.com

\begin{abstract}
Climatic conditions such as relatively cold temperatures and dryness are able to limit malaria transmission. Climate change is therefore expected to alter malaria spread. A previous assessment of the potential impacts of climate change on the seasonality of malaria in Africa is revisited. Bias-corrected regional climate projections with a horizontal resolution of $0.5^{\circ}$ are used from the Regional Model (REMO), which include land use and land cover changes. The malaria model employed is the climate-driven seasonality model (MSM) from the Mapping Malaria Risk in Africa project for which a comparison with data from the Malaria Atlas Project (MAP) and the Liverpool Malaria Model (LMM), and a novel validation procedure lends more credence to results. For climate scenarios A1B and B1 and for 2001-2050, REMO projects an overall drying and warming trend in the African malaria belt, that is largely imposed by the man-made degradation of vegetation. As a result, the malaria projections of the MSM show a decreased length of the malaria season in West Africa. The northern Sahel is no more longer suitable for malaria in the projections and shorter malaria seasons are expected for various areas farther south. In East Africa, higher temperatures and nearly unchanged precipitation patterns lead to longer transmission seasons and an increase in highland malaria. Assuming constant population numbers, an overall increase in person-months of
\end{abstract}

Electronic supplementary material The online version of this article (doi:10.1007/s10584-013-0851-z) contains supplementary material, which is available to authorized users.

V. Ermert $(\bowtie) \cdot$ A. H. Fink

Institute of Geophysics and Meteorology, University of Cologne,

Kerpener Straße 13, 50923 Cologne, Germany

e-mail: vermert@meteo.uni-koeln.de

H. Paeth

Institute of Geography, University of Würzburg, Am Hubland, 97074 Würzburg, Germany 
exposure of up to $6 \%$ is found. The results of this simple seasonality model are similar to previous projections from the more complex LMM. However, a different response to the warming of highlands is found for the two models. It is concluded that the MSM is an efficient tool to assess the climate-driven malaria seasonality and that an uncertainty analysis of future malaria spread would benefit from a multi-model approach.

\section{Introduction}

The climate system of the Earth strongly affects human life and has a wide range of health impacts. It is well known that the warm and humid climate conditions in the tropics are suitable for diseases like malaria (Githeko et al. 2000). In Africa, temperatures are mostly suitable for malaria transmission and optimal breeding conditions for mosquitoes are provided by rainy seasons (Hay et al. 2000). The Intergovernmental Panel on Climate Change (IPCC) projected that malaria areas will be differently affected by climate change (Confalonieri et al. 2007).

One important aspect of malaria is its seasonality. The assessment of the impact of climate change on malaria should include the malaria transmission period. Longer malaria seasons might be of a similar importance as an expansion of the geographic area suitable for malaria. Short periods of exposure are often not able to result in an immune response, whereas longer transmission seasons reduce the epidemic risk. Knowledge in terms of the malaria seasonality has important implications for malaria control (Tanser et al. 2003).

The Mapping Malaria Risk in Africa (MARA) project (MARA 1998), especially Tanser et al. (2003), introduced a simple climate-driven malaria seasonality model (hereafter termed MSM: MARA Seasonality Model). The MSM was used by Tanser et al. (2003) to show the impact of climate change on the seasonality of malaria in Africa. The malaria projections were based on climate scenarios from the Hadley Centre global climate model (HadCM3) (Johns et al. 2003). A malaria seasonality length increase was found for highlands as well as existing malaria areas. Only a small change occurred in the latitudinal extent of malaria.

These results were based on the use of coarse $\left(2.5^{\circ} \times 3.75^{\circ}\right.$ latitude/longitude $)$, non bias-corrected meteorological data from a global climate model. The potentially important impacts of Land Use and land Cover (LUC) changes on African climate were not considered. In the present study, the results from Tanser et al. (2003) are therefore reassessed using bias-corrected and higher resolution data from A1B and B1 climate scenario ensemble runs performed with the REgional MOdel (REMO). REMO was the first regional climate model including LUC changes for Africa in a comprehensive modeling approach (Paeth et al. 2009). The REMO projection was recently also used by Ermert et al. (2012) to drive the Liverpool Malaria Model (LMM).

The original validation of the MSM was criticised by Reiter et al. (2004) since it was based only on malaria infection rates of humans. This is potentially problematic, since the clearance of parasites from the blood takes often longer than a month. For this reason, this study compares the MSM simulated geographical distribution and seasonality length of malaria with previous assessments and carried out a novel and more appropriate validation procedure. 
Many other factors can affect malaria and some may compensate for the impact of climate (Lafferty 2009; Béguin et al. 2011). In the last decade there was a resurgence of financing malaria control (Snow et al. 2008) causing enormous efforts to combat malaria (World Health Organization 2008) such as the distribution of insecticidetreated nets (Noor et al. 2009). Recently, Gething et al. (2010) showed that despite global warming during the 20th century (20C) a global recession of malaria was observed. The economic development and malaria control during the last century (Hay et al. 2004) contracted the spread of malaria in particular outside of Africa (Hay et al. 2004). Gething et al. (2010) reported also a decline in the malaria endemicity for most areas of Africa. Control measures also played an important role in Africa. However, the decline in endemicity in parts of Africa might also be caused by changed rainfall patterns, which were not considered by Gething et al. (2010). After the drought in the Sahel in the 1970s (Nicholson 2005), a decrease in malaria transmission was, for example, observed in Senegal and Niger (Mouchet et al. 1996; Julvez et al. 1997). This suggests a strong impact of rainfall on the malaria occurrence in the Sahel.

Various studies argued that climate warming seems not to be responsible for observed changes in transmission (e.g. Mouchet et al. 1998; Reiter 2001; Hay et al. 2002a, b, c). However, this statement remains controversial since other studies stated that the observed malaria changes were caused by increased temperatures (e.g. Epstein et al. 1998; Pascual et al. 2008; Omumbo et al. 2011). Patz et al. (2002) found that the methods used by Hay et al. (2002a) were incorrect. Recently, Omumbo et al. (2011) used atmospheric measurements from the Kenyan Highlands and pointed out that the climate conditions remain a potential driver of malaria. According to Pascual et al. (2008) both theories might be correct since various factors complement and interact each other at different time scales. The focus of the present study is limited to the influence of climate on malaria transmission taking LUC impacts on climate change into account.

\section{Methods}

\subsection{REMO climate scenarios}

The following MSM runs are forced by ensemble data from REMO (see Paeth et al. 2009). The control period is based on 1960-2000 representing the 20C and future projections according to $\mathrm{A} 1 \mathrm{~B}$ and $\mathrm{B} 1$ emission scenarios were simulated for 2001-2050. Included in the REMO projections are LUC changes resulting in a strong decrease in precipitation for most parts of West and Central Africa. Higher rainfall amounts were projected over the Guinean mountains and the Horn of Africa. Temperature increases between about $1-3^{\circ} \mathrm{C}$ were simulated by REMO until 2050. The REMO preciptation and temperature data was bias-corrected to ensure realistic input values for the MSM. For more details see Online Resource 1.

\subsection{MARA Seasonality Model (MSM)}

The present study applies the MARA Seasonality Model (MSM) as defined by Tanser et al. (2003). Long-term mean monthly precipitation and temperature data 
Table 1 Criteria of the MSM to calculate months suitable for malaria transmission in Africa (Tanser et al. 2003)

\begin{tabular}{|c|c|c|c|}
\hline \# & Sym & Parameter & Criteria \\
\hline 1 & $T_{\min , \mathrm{m}}$ & Monthly minimum temperature & $T_{\min , \mathrm{m}} \geq 5^{\circ} \mathrm{C}$ for every month \\
\hline 2 & $T_{3 m}$ & $\begin{array}{l}\text { Three-month moving average } \\
\text { temperature }\end{array}$ & $T_{3 m} \geq 19.5^{\circ} \mathrm{C}+\sigma\left(T_{m}\right)$ \\
\hline 3 & $P_{3 m}$ & $\begin{array}{l}\text { Three-month moving average } \\
\text { monthly precipitation }\end{array}$ & $P_{3 m} \geq 60 \mathrm{~mm}$ \\
\hline 4 & $P_{c}$ & Catalyst month of precipitation & One month: $P_{c} \geq 80 \mathrm{~mm}$ \\
\hline 5 & - & Assigned transmission status & $\begin{array}{l}\text { Fulfilled criteria } 1-4 \text { (one month } \\
\text { interruption is allowed) }\end{array}$ \\
\hline
\end{tabular}

Columns: \#: criteria number; sym: symbol of the applied parameter; parameter: name of the parameter; criteria: criteria used to calculate months suitable. $\sigma\left(T_{m}\right)$ : standard deviation of the monthly mean temperatures. For further details see Online Resource 1

is the basis of the MSM, which uses a Boolean logic approach. Five different temperature and precipitation criteria were formulated regarding the climatic suitability of malaria (see Table 1). For further information see Online Resource 1.

\subsection{Validation of the MSM simulations}

In addition to the validation from Tanser et al. (2003), further credence is provided for the MSM via validating the geographic malaria distribution of the MSM against data from the Malaria Atlas Project (MAP; Hay et al. 2009) and against simulated data from the 2010 version of the Liverpool Malaria Model $\left(\mathrm{LMM}_{2010}\right.$; see Ermert et al. 2011a, b, 2012, for details). In addition, the MSM simulation was validated against single observations from 65 malaria field surveys from West Africa. The malaria season was derived via observed monthly Entomological Inoculation Rates ( $E I R_{m}$; i.e. the number of infectious mosquito bites per human per month). Evaluated were the MSM simulations with regard to the length of the malaria season (Seas) as well as the start (SSeas) and end (ESeas) of the malaria season. For more details see Online Resource 1.

\section{Results}

\subsection{Validation of the MSM malaria distribution}

The geographic distribution of the malaria spread (Fig. 1; for details see Online Resource 1) is in general comparable to the MAP and $\mathbf{L M M}_{2010}$ data. Regarding MAP, the MSM might underestimate the spread of malaria in parts of the Horn of Africa. In comparison to the $\mathrm{LMM}_{2010}$, the season length is shorter in highland territories and in parts of West Africa. Due to the sparsity of validation data it is 


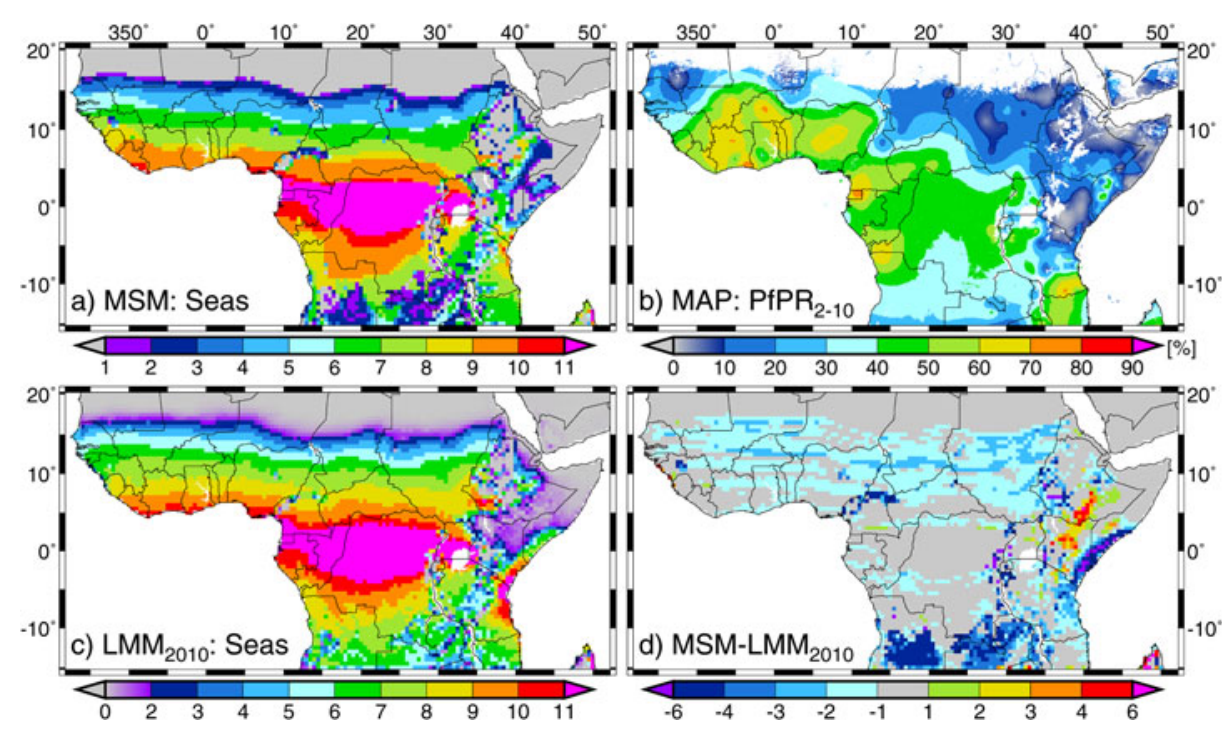

Fig. 1 Comparison of the MSM malaria distribution with the map of malaria endemicity of the Malaria Atlas Project (MAP; Hay et al. 2009) and with data from the 2010 version of the Liverpool Malaria Model (LMM 2010 ; Ermert et al. 2011a, b): a MSM simulated length of the malaria season (Seas; in months) for 1960-2000 based on REMO temperature and precipitation data. b MAP model predicted Plasmodium falciparum parasite ratio of children between 2 and 10 years $\left(P f P R_{2-10}\right.$; in $\left.\%\right)$ of 2007 on the original $5 \mathrm{~km} \times 5 \mathrm{~km}$ latitude-longitude resolution. c LMM 2010 simulated Seas (in months) for 1960-2000 based on REMO temperature and precipitation data. d Difference in the Seas values (in months) of 1960-2000 between the MSM and LMM 2010

difficult to judge which model is more accurate in terms of the simulation of the malaria seasonality.

\subsection{Validation of the MSM at single locations}

The validation of the MSM via the usage of observed entomological inoculation rates shows (for details see Online Resource 1) that the simulated season length of the MSM is in general in the range of field observations from West Africa. In few cases, the difference between observed data and simulated values exceeded two months. In about 43 and $77 \%$ of the 65 paired values the MSM is able to accurately predict Seas within one and two months, respectively (see Online Resource 1, Fig. 1). The model also accurately simulates the start and end of the malaria season. In about 75 and $70 \%$ of the cases the model is able to accurately predict SSeas and ESeas within one month, respectively. However, the MSM seems to simulate more frequently too early starts of the malaria season. A slight skewness of distribution is also found with regard to the length and end of the malaria season. Despite the variability of single observations against the MSM simulated climate average values, the MSM simulates values comparable with observations. Even in the absence of long-term 
field observations, the EIR-based validation of the MSM lends additional credence on its suitability to indicate a climate-controlled malaria seasonality.

\subsection{Malaria seasonality under 20C climate conditions}

The distribution of rainfall and temperatures in space and time from the REMO 20C climate run (1960-2000) determine the simulated malaria seasonality of the MSM. Only a small area in the heart of the African continent exhibits no climatic constraints on malaria (see Fig. 2, which shows monthly maps and causes of constraints). For other grid boxes the MSM criteria are not satisfied for at least part of the year. The regions north and south of the equator are characterised by low precipitation amounts during boreal winter and summer, respectively. During boreal winter and summer, temperatures fall to such low values that malaria transmission ceases in the model north and south of about $15^{\circ} \mathrm{N}$ and $10^{\circ} \mathrm{S}$, respectively. Temperatures further limit the spread of malaria in the East African highlands. At few grid points in Ethiopia even the $T_{\min , \mathrm{m}}$ threshold impedes malaria transmission in the model.

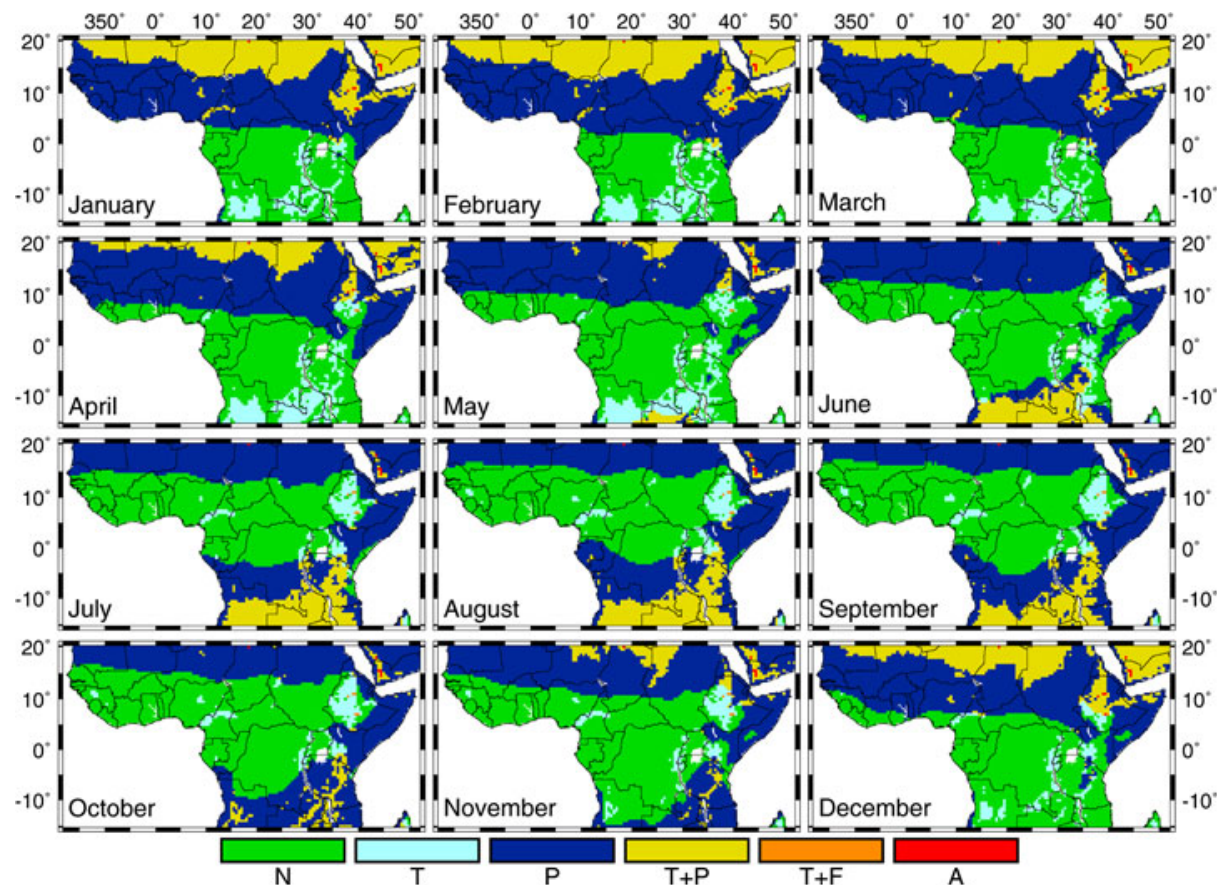

Fig. 2 Malaria transmission suitability and constraints of the 20C climate (1960-2000) with regard to the MSM criteria. Displayed are areas and months where and when the first four criteria of the MSM (see Table 1) are fulfilled (N: no constraints; green colour) or where at least one criterion is not fulfilled (all other colours). Unfulfilled criteria are differentiated into five categories: T (light blue): criterion $2\left(T_{3 m}\right)$ is not fulfilled; $\mathrm{P}$ (dark blue): criterion $3\left(P_{3 m}\right)$ or $4\left(P_{c}\right)$; $\mathrm{T}+\mathrm{P}($ yellow $)$ : criterion 1 $\left(T_{3 m}\right)$ and criterion $3\left(P_{3 m}\right)$ or $4\left(P_{c}\right) ; \mathrm{T}+\mathrm{F}($ orange $)$ : criteria $2\left(T_{3 m}\right)$ and $1\left(T_{\min , \mathrm{m}}\right) ; \mathrm{T}+\mathrm{F}+\mathrm{P}($ red $)$ : criteria $1\left(T_{\min , \mathrm{m}}\right), 2\left(T_{3 m}\right)$ and criterion $3\left(P_{3 m}\right)$ or $4\left(P_{c}\right)$. For details on the definition of the criteria and variables see Table 1 . The MSM is driven by REMO data 
In Africa, precipitation limits the spread of malaria in various areas. No transmission is hence predicted for regions with low annual precipitation amounts, for example, in the Sahara desert, along the Horn of Africa, and in the vicinity of Lake Turkana (Kenya). In agreement with the $20 \mathrm{C}$ rainfall distribution, the MSM reveals a decrease in season length from equatorial Africa towards the Sahel (Fig. 3a). Malaria transmission is year-round in the equatorial tropics.

The MSM also correctly reproduces the gap in the malaria spread in the East African highlands. The MSM simulates malaria-free areas along the Great Rift Valley, for example, in the Ethiopian Highlands. The higher altitudes of the Fouta Djallon in Guinea, as well as the Jos and Adamawa Plateaus in Nigeria and Cameroon markedly reduce the season length or even cause no malaria transmission in the MSM (Fig. 3a).

In West Africa, the start of malaria transmission is simulated shortly after the onset of the rainy season. The malaria season sets in between March and April and finally ends in November or December at the Guinean coast (Fig. 3b and c). The MSM reproduces the observed delayed malaria seasonality toward the Sahara. The model furthermore depicts two distinct malaria seasons in various parts of East Africa. For most regions south of the near-equatorial tropics, malaria transmission is simulated between boreal autumn and early boreal summer. However, due to low temperatures at several grid points in Angola and Zambia, seasonality is restricted between November and January. For some grid points of this area the malaria season breaks between February and March resulting in a bimodal malaria season (Online Resource 1, Fig. 2).

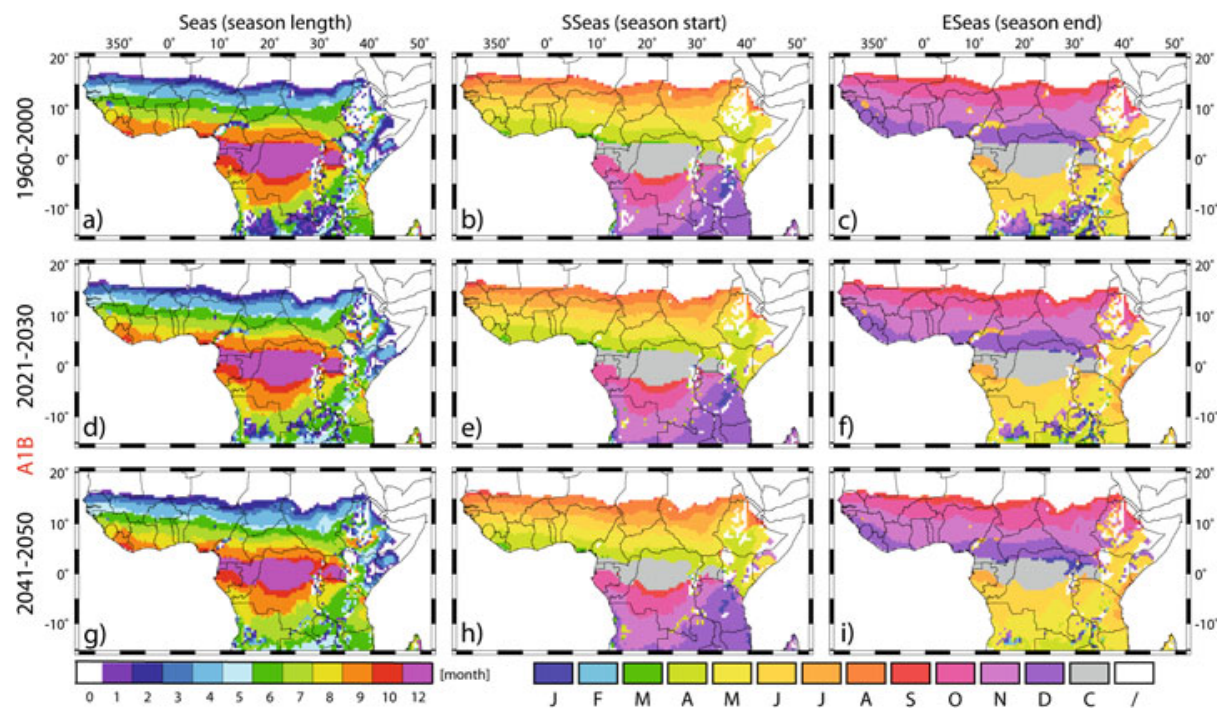

Fig. 3 MSM simulations of (a, d, and $\mathbf{g})$ the length of the malaria season (Seas; in number of months), $(\mathbf{b}, \mathbf{e}$, and $\mathbf{h})$ the start month (SSeas), and (c, f, and i) the end month (ESeas) of the malaria season. Illustrated are values for (a-c) the 20C period (1960-2000) as well as for (d-f) 2021-2030 and (g-i) 2041-2050 of the A1B scenario. Regarding SSeas and ESeas only the first season is shown for areas with two malaria seasons (see Online Resource 1, Figs. 2 and 5 for the second malaria season). The characters ' $\mathrm{C}$ ' and '/ denote year-round and no malaria transmission, respectively 
According to population data from 2000 (Online Resource 1, Fig. 3b CIESIN 2005) and the MSM simulation about 427 million people are exposed to malaria in tropical Africa (i.e. the model domain). Altogether, 2.873 billion person-months of exposure (PME; see Online Resource 1) are computed for the studied area (Online Resource 1, Table 1). High PME values are found in southern Nigeria, eastern Rwanda, and parts of Uganda (Online Resource 1, Fig. 3a).

\subsection{Malaria seasonality under the projected climate change}

The assessment of the impact of climate change on malaria seasonality is now performed by means of data from MSM simulations. MSM runs are based on the projected atmospheric conditions of five decades between 2001 and 2050 and are presented for the 2020s and 2040s, respectively. Assuming constant population numbers, the projected atmospheric changes under the A1B scenario lead to an increase in the MSM simulated malaria exposed population from about 427 to about 461 million people in the 2040s (Online Resource, Table 1). The value for PME rises from about 2.873 to 3.057 billion in the study area (see also Online Resource 1, Fig. 3c-f).

Reduced precipitation amounts in the REMO climate projections lead to a decrease in the length of the malaria season and PME in most parts of tropical Africa (Fig. 3d, g and Online Resource 1, Fig. 3c-f). Most pronounced is the reduction in the malaria presence in the Sahel as well as in the Soudanian zone. A southward shift of about $2^{\circ}$ is projected for West Africa leading to a withdrawal of malaria in the northern part of the Sahel (i.e. north of about $16^{\circ} \mathrm{N}$ ). A later onset and earlier end of malaria transmission is expected for areas further south (e.g. Fig. 3h and i). In central Burkina Faso and along the coast of Benin, for example, the start of transmission is retarded from July to August and from April to May, respectively. In contrast, malaria transmission ceases about one month earlier. The shorter malaria season leads to a strong decline of PME especially in south-western Nigeria (Online Resource 1, Fig. 3). An extended period of malaria transmission and higher PME values are found for the Fouta Djallon as well as the Adamawa and Jos Plateaus. At the Adamawa Plateau, for example, for certain grid boxes a five months longer transmission is found (Fig. $3 \mathrm{a}$ and $\mathrm{g}$ ) due to the temperature rise of about $2^{\circ} \mathrm{C}$.

An extended transmission period is projected for the Greater Horn of Africa as well as for Angola and Zambia (Fig. 3d and g). Higher temperatures and nearly unchanged precipitation amounts cause an increase in the season length and PME for these regions. The presence of highlands causes a fairly complex change pattern. Temperatures are projected to increase mostly between 1.5 and $3.5^{\circ} \mathrm{C}$ in the $2040 \mathrm{~s}$. The MSM projects therefore a reduction of climatically unsuitable malaria areas. The length of the malaria season increases along the Eastern Rift Valley comprising the Ethiopian Highlands, the Western Kenyan Highlands, as well as the Eastern Arc Mountains of Tanzania (see e.g. Fig. 3a and g). Malaria transmission rises further in the Western Rift Valley in the area of southwestern Uganda, Rwanda, and Burundi. The strong increase in the season length of up to six months in parts of highland areas of Angola and Zambia is notable. The longer malaria seasons lead to additional millions of PME in parts of the highlands of Rwanda, Burundi, Kenya, and Ethiopia (e.g. Online Resource, Fig. 3f). The onset and end of the malaria transmission is projected to be earlier and later in comparison with the $20 \mathrm{C}$ climate, respectively. In 
addition, a second malaria season is projected to develop between about November and December for parts of Ethiopia, Kenya, and Somalia (Online Resource 1, Figs. 2 and 5) due to a small increase in precipitation.

\subsection{A1B versus B1}

Results regarding runs for scenarios $\mathrm{A} 1 \mathrm{~B}$ and $\mathrm{B} 1$ reveal a similar change of the malaria seasonality (see Online Resource 1, Figs. 4, 5 and 6). However, the stronger changes are projected by the A1B than by the B1 scenario. The comparison of change signals with regard to individual decades reveals a time lag of one to two decades between the $\mathrm{A} 1 \mathrm{~B}$ and $\mathrm{B} 1$ scenario with regard to season changes. However, the overall PME changes are fairly similar (Online Resource, Table 1). The reduction or enhancement of the malaria transmission and PME under the B1 scenario is for most areas somewhat lower. The reader is referred to the supplemental material (Online Resource 1, Figs. 4-6) for a detailed analysis of the projected malaria season and PME changes under scenario B1.

\section{Discussion}

The principal goal of the present study was an update of the assessment of malaria seasonality changes in Africa undertaken by Tanser et al. (2003). For the first time, MSM simulations were based on a high-resolution data set from a regional climate model taking both increasing greenhouse-gas concentrations and LUC changes into account. Due to the latter, most parts of Africa are projected to become drier and warmer (Paeth et al. 2009). As a consequence, the present study shows a much better regional detail of changes in the malaria season, especially over the East African mountains, and several differences when compared to already published malaria projections, in particular to that of Tanser et al. (2003). The application of the $0.5^{\circ}$ resolution enables to study much smaller spatial structures especially in highland territories (see also discussion in Ermert et al. (2012)).

The present study supplements previous assessments of malaria changes in Africa. For example, Martens et al. (1995, 1999), Lindsay and Martens (1998), van Lieshout et al. (2004) applied a process-based mathematical biological malaria model. In their projections, malaria transmission increased at high altitudes and decreased under dryer conditions at the end of the 21st century. These results are in agreement with Hartman et al. (2002), Ebi et al. (2005), and Thomas et al. (2004) who used the rulesbased MARA climatic suitability model (Craig et al. 1999). The first two studies showed the importance of considering different climate scenarios of various general circulation models to project malaria changes in Zimbabwe. Rogers and Randolph (2000) ran a statistic model exploiting maximum likelihood methods, which produced small changes in the malaria spread by 2050 . Peterson (2009) used an ecological niche model resulting in a decrease of the vector suitability in West Africa and an increase in East and South Africa. Béguin et al. (2011) applied a logistic regression model accounting for climatic and socio-economic factors indicating that economic growth may offset climate-related increases of malaria. Egbendewe-Mondzozo et al. (2011) make use of semi-parametric methods relating climate and socio-economic 
control variables with reported malaria cases from 25 African countries. An increase in malaria cases is projected in most of the countries for 2080-2100.

The malaria projections have several limitations in common: (i) They are all based on coarse input data from general circulation models that were either statistically downscaled or simply interpolated to mimic a higher spatial resolution. (ii) No biascorrection was applied to the climate data which would reduce the large uncertainties in the projections. (iii) The impact of rainfall is mostly poorly represented in the malaria modeling frameworks. (iv) The process-based models include non-quantified important model parameters and the empirical models suffer from the fact that they are not able to include all relevant predictors and they assume that the statistical relationship is unchanged in future. (v) Only few studies include other factors than climate.

Like the aforementioned malaria models also the MSM has conceptual problems (Rogers and Randolph 2006). Tanser et al. (2003) used only comparatively few references for the definition of the climatic thresholds. The construction of the model is only based on field observations and climatic data from 15 African locations and focuses on low and not high temperature limits (see Craig et al. 1999). In addition, the model does not take into account characteristics of numerous vector species. A different relation to rainfall was, for example, found for Anopheles moucheti (Awolola et al. 2002). The main criticism, however, was directed at the MSM because of the inadequacy of the original validation procedure. This prompted the present study to compare the MSM results with a published malaria map and a more complex malaria model, as well as to carry out a novel and more appropriate validation (see methods). The simulated malaria distribution of the MSM is generally comparable with the data from the MAP and the $\mathrm{LMM}_{2010}$. In terms of the length of the malaria season mostly small differences are found between the MSM and $\mathrm{LMM}_{2010}$. The greatest differences are diagnosed for the highland areas, where the MSM shows a different response to temperatures below and around $20^{\circ} \mathrm{C}$. Furthermore, observed monthly entomological inoculation rates were utilised instead of parasitological field observations (compare Tanser et al. 2003). The use of the latter was in the focus of the criticism of Reiter et al. (2004). The MSM was validated by data from about 65 field studies in West Africa. Since the field observations of single years were found to scatter mostly within two months around the climate average value of the model, the validation of the MSM significantly augments the credence of the presented results.

Tanser et al. (2003) and the present study estimate about the same PME values (3.1 vs. 2.9 billion) and number of exposed people (445 vs. 427 million) for 1995 and 2000, respectively. The former study considered the whole of Africa, whereas here only tropical Africa is examined. Tanser et al. (2003) estimated an overall increase of PME for Africa of about 16-28\% by 2100 . The present study, projects an increase in PME for tropical Africa of about 3-4 and $6 \%$ for the 2020s and 2040s, respectively.

One of the most important results of the present study is the marked decrease in the length of the malaria season and PME in the Sahel and Sudanian zone. Besides the simulated withdrawal of malaria in the northern Sahelian zone, the season length shortens, for example, along the Guinean coast leading to a strong decline in the PME values. The $\mathrm{LMM}_{2010}$, using the same REMO climate projections and a more complex malaria model, simulated about the same changes in the length of the malaria season for West Africa (Ermert et al. 2012). In this region, the comparison between the MSM and $\mathrm{LMM}_{2010}$ change signal reveals only small differences (see Online Resource 1, Fig. 7). The projected malaria simulations from the MSM and $\mathrm{LMM}_{2010}$ differ from those of Tanser et al. (2003) who found a substantial expanded 
PME in existing malaria regions. For example, Tanser et al. (2003) find no decline in the PME values for Nigeria. Their study also projected no marked change in the latitudinal extent of malaria in the Sahel. In their A2a-based projection, a moister climate pushes the malaria transmission even further to the north. This is similar to the projection of an transmission potential model, which simulated an increase of the vulnerability in the Sahel using different HadCM3 runs (van Lieshout et al. 2004). Moreover, the statistical model of Rogers and Randolph (2000) resulted in a small spatial extent of malaria distribution in the Sahel regarding the HadCM2 scenario. In contrast, Peterson (2009) applied ecological niche models, which showed similar change patterns like the present study. According to Peterson (2009), future conditions are simulated to become unsuitable for mosquito species in parts of the Sahel. Thomas et al. (2004) used a biological malaria model as produced by the MARA collaboration. Their malaria simulations projected also a reduced climatic suitability for parts of the Sahel centered on southern Mali for 2055 and 2085. It should be noted that the results of climate-malaria model simulations remain sensitive to the used climate scenarios, which differ from the scenarios as applied by Tanser et al. (2003).

Another expected result of the present MSM simulation is the increase of the malaria distribution, as well as of the length of the malaria season in highland areas. These changes are mainly caused by higher temperatures in climate scenarios A1B and B1. In particular, the gap in malaria transmission in East African highlands decreases markedly. However, the malaria changes in altitude are model dependent as is shown by the comparison between the results of MSM and $\mathrm{LMM}_{2010}$, which are both driven by the REMO data. In case of the $\mathrm{LMM}_{2010}$ (Ermert et al. 2012), the increase of the malaria seasonality for areas below about $1500 \mathrm{~m}$ is not as pronounced as in the MSM projections (Online Resource 1, Fig. 7). In contrast, above this altitude, in many parts of the Ethiopia highlands for example, the $\mathrm{LMM}_{2010}$ reveals a stronger response of the season length to global warming. This is again related to the different response of the MSM and $\mathrm{LMM}_{2010}$ to temperatures, which are slightly above the sporogonic temperature threshold. This illustrates the uncertainty, which is linked to the choice of the malaria model.

The findings that highland malaria is increased are in principal agreement with the malaria projections from Tanser et al. (2003). They found an altitudinal increase in the malaria spread that is mostly pronounced at the end of the 21 st century. Like in the present study, the strongest PME increases were found for Kenya, Ethiopia, Burundi, and Rwanda. Also other studies found increases in transmission in many parts of the Horn of Africa (Rogers and Randolph 2000; Peterson 2009; Thomas et al. 2004; Lindsay and Martens 1998; Ebi et al. 2005).

The present study reveals some overall commonalities to earlier results. For example, usually malaria-free areas and those with unstable malaria occurrence were mostly affected. As stated in the IPCC-AR4, climate change may cause an increase and reduction of malaria areas (Confalonieri et al. 2007). A limitation of the present study relates to the fact that the atmospheric data set covers only two different climate scenarios from one single regional climate model. Paeth et al. (2010) recently showed results for nine regional climate models, but except for the REMO model, none considered LUC changes. The REMO results and those of Koster et al. (2004) suggest that meaningful climate projections for Africa should include changes in the land surface (Christoph et al. 2010). In this context it is important to note that the results from Paeth et al. (2009) suggest for the African domain that LUC changes 
seem to be as important as the choice of the greenhouse gas scenario and that, as a consequence, the anthropogenic climate change signal is enhanced and occurs earlier than in greenhouse gas-only simulations. In conclusion, the REMO drying and warming trend is a plausible climate projection and the new MSM data provided herein might render helpful information for decision makers in terms of malaria control of highland areas and rather dry territories such as the Sahel.

\section{Conclusions}

This study reassessed the potential impact of climate change on the malaria distribution in tropical Africa. For the first time, MSM simulations were based on a highresolution data set from a regional climate model taking both increasing greenhousegas concentrations and LUC changes into account. An overall drying and warming trend in the African malaria belt, which is largely imposed by the man-made degradation of vegetation, is a plausible climate scenario for the upcoming decades. As a result, the malaria projections show a decreased length of the malaria season in West Africa. The northern Sahel is no longer suitable for malaria in the projections and shorter malaria seasons are expected for various areas farther south. In East Africa, the projected higher temperatures and nearly unchanged precipitation patterns lead to longer transmission seasons and an extension of highland malaria territories in the model simulations. Assuming constant population numbers, a net increase in PME of up to $6 \%$ is found for tropical Africa. In comparison to the $\mathrm{LMM}_{2010}$, a different response of the MSM to altitude was detected. This clearly reveals the importance of multi-model uncertainty analysis for the projection of the future malaria spread.

It is concluded that the MSM can be a useful tool for the IPCC assessment reports to study the effect of climate change on the malaria seasonality. The MSM is a simple malaria model requiring only monthly climate data as its input and causes only a small computational load. The present study aimed only at assessing the potential impact of climate on malaria in isolation. It is clear that this does not necessarily translate into disease risk changes. A much wider analysis that includes other factors influencing malaria are required to achieve this goal.

Acknowledgements This study was part of the IMPETUS West-Africa project and was supported by the Federal German Ministry of Education and Research (BMBF) under grant No. 01 LW 06001A in the GLOWA programme and by the Ministry of Innovation, Science, Research and Technology (MIWFT) of the federal state of North Rhine-Westphalia under grant No. 313-21200200. The first two authors were partly funded by the EU project QWeCI (Quantifying Weather and Climate Impacts on health in developing countries; funded by the European Commission's Seventh Framework Research Programme under the grant agreement 243964). We are grateful to Adrian M. Tompkins for proofreading the manuscript and to four anonymous reviewers for their comments that greatly improved the article.

Open Access This article is distributed under the terms of the Creative Commons Attribution License which permits any use, distribution, and reproduction in any medium, provided the original author(s) and the source are credited.

\section{References}

Awolola TS, Okwa O, Hunt RH, Ogunrinade AF, Coetzee M (2002) Dynamics of the malaria-vector populations in coastal Lagos, south-western Nigeria. Ann Trop Med Parasitol 96:75-82 
Béguin A, Hales S, Rocklö J, Åström C, Louis VR, Sauerborn R (2011) The opposing effects of climate change and socio-economic development on the global distribution of malaria. Glob Environ Chang 21:1209-1214

Christoph M, Fink AH, Paeth H, Born K, Kerschgens M, Piecha K (2010) Climate scenarios. In: Speth P, Christoph M, Diekkrüger B, Bollig M, Fink AH, Goldbach H, Heckelei T, Menz G, Reichert B, Rössler M (eds) Impacts of global change on the hydrological cycle in west and northwest Africa. Springer, Heidelberg, pp 402-425

CIESIN (2005) Gridded Population of the World, Version 3 (GPWv3) Data collection. Center for International Earth Science Information Network (CIESIN), Centro Internacional de Agricultura Tropical (CIAT), Columbia University, Palisades, NY, USA. Available online at http://sedac.ciesin.columbia.edu/gpw/index.jsp

Confalonieri U, Menne B, Akhtar R, Ebi KL, Hauengue M, Kovats RS, Revich B, Woodward A (2007) Human health. In: Parry ML, Canziani OF, Palutikof JP, van der Linden PJ, Hanson CE (eds) Climate change 2007: impacts, adaptation and vulnerability. Contribution of working group II to the fourth assessment report of the intergovernmental panel on climate change. Cambridge University Press, Cambridge, pp 391-431

Craig MH, Snow RW, le Sueur D (1999) A climate-based distribution model of malaria transmission in sub-Saharan Africa. Parasitol Today 15:105-111

Ebi KL, Hartman J, Chan N, McConnell J, Schlesinger M, Weyant J (2005) Climate suitability for stable malaria transmission in Zimbabwe under different climate change scenarios. Clim Change 73:375-393

Egbendewe-Mondzozo A, Musumba M, McCarl BA, Wu X (2011) Climate change and vector-borne diseases: An economic impact analysis of malaria in Africa. Int J Environ Res Public Health 13:913-930

Epstein PR, Diaz HF, Elias S, Grabherr G, Graham NE, Martens WJM, Moseley-Thompson E, Susskind J (1998) Biological and physical signs of climate change: focus on mosquito-borne diseases. Bull Am Meteorol Soc 79:409-417

Ermert V, Fink AH, Jones AE, Morse AP (2011a) A new version of the Liverpool Malaria Model. I. Review of the parameter setting and model structures. Malar J 10:35

Ermert V, Fink AH, Jones AE, Morse AP (2011b) A new version of the Liverpool Malaria Model. II. Calibration and validation for West Africa. Malar J 10:62

Ermert V, Fink AH, Morse AP, Paeth H (2012) The Impact of Regional Climate Change due to Greenhouse Forcing and Land-Use Changes on Malaria Risk in Tropical Africa. Environmental Health Perspectives 120:77-84. doi:10.1289/ehp.1103681

Gething PW, Smith DL, Patil AP, Tatem AJ, Snow RW, Hay SI (2010) Climate change and the global malaria recession. Nature 465:342-345

Githeko AK, Lindsay SW, Confalonieri UE, Patz JA (2000) Climate change and vector-borne diseases: a regional analysis. Bull World Health Org 78:1136-1147

Hartman J, Ebi K, McConnell KJ, Chang N, Weyant J (2002) Climate suitability: for stable malaria transmission in Zimbabwe under different climate change scenarios. Global Change and Human Health 3:42-54

Hay SI, Omumbo JA, Craig MH, Snow RW (2000) Earth observation, geographic information systems and Plasmodium falciparum malaria in sub-Saharan Africa. Adv Parasitol 47:173-215

Hay SI, Cox J, Rogers DJ, Randolph SE, Stern DI, Shanks GD, Myers MF, Snow RW (2002a) Climate change and the resurgence of malaria in the East African highlands. Nature 415:905909

Hay SI, Cox J, Rogers DJ, Randolph SE, Stern DI, Shanks GD, Myers MF, Snow RW (2002b) Regional warming and malaria resurgence. Nature 420:628

Hay SI, Rogers DJ, Randolph SE, Stern DI, Cox J, Shanks GD, Snow RW (2002c) Hot topic or hot air? Climate change and malaria resurgence in East African highlands. Trends Parasitol 18:530534

Hay SI, Guerra CA, Tatem AJ, Noor AM, Snow RW (2004) The global distribution and population at risk of malaria: past, present, and future. Lancet Infect Dis 4:327-336

Hay SI, Guerra CA, Gething PW, Patil AP, Tatem AJ, Noor AM, Kabaria CW, Manh BH, Elyazar IRF, Brooker SJ, Smith DL, Moyeed RA, Snow RW (2009) A world malaria map: Plasmodium falciparum endemicity in 2007. Public Library of Science Medicine 6:e1000,048

Johns TC, Gregory JM, Ingram WJ, Johnson CE, Jones A, Lowe JA, Mitchell JFB, Roberts DL, Sexton DMH, Stevenson DS, Tett SFB, Woodage MJ (2003) Anthropogenic climate change for 1860 to 2100 simulated with the HadCM3 model under updated emission scenarios. Clim Dyn 20:583-612 
Julvez J, Mouchet J, Michault A, Fouta A, Hamidine M (1997) Evolution du paludisme dans l'est sahélien du Niger. Une zone écologiquement sinistrée. Bull Soc Pathol Exot 90:101-104

Koster RD, Dirmeyer PA, Guo Z, Bonan G, Chan E, Cox P, Gordon CT, S SK, Kowalczyk E, Lawrence D, Liu P, Lu CH, Malyshev S, McAvaney B, Mitchell K, Mocko D, Oki T, Oleson K, Pitman A, Sud YC, Taylor CM, Verseghy D, Vasic R, Xue Y, Yamada T (2004) Anthropogenic climate change for 1860 to 2100 simulated with the HadCM3 model under updated emission scenarios. Science 305:1138-1140

Lafferty KD (2009) The ecology of climate change and infectious diseases. Ecology 90:888-900

Lindsay SW, Martens WJM (1998) Malaria in the African highlands: past, present and future. Bull World Health Org 76:33-45

MARA (1998) Towards an atlas of malaria risk in Africa: first technical report of the MARA/ARMA collaboration. First technical report, MARA/ARMA, Durban, South Africa

Martens P, Kovats RS, Nijhof S, de Vries P, Livermore MTJ, Bradley DJ, Cox J, McMichael AJ (1999) Climate change and future populations at risk of malaria. Glob Environ Change 9:S98S107

Martens WJM, Niessen LW, Rotmans J, Jetten TH, McMichael AJ (1995) Potential impact of global climate change on malaria risk. Environ Health Perspect 103:458-464

Mouchet J, Faye O, Julvez J, Manguin S (1996) Drought and malaria retreat in the Sahel, West Africa. Lancet 348:1735-1736

Mouchet J, Manguin S, Sircoulon K, Lavnevale S, Faye O, Onapa AW, Carnevale P, Julvez J, Fontenille D (1998) Evolution of malaria in Africa for the past 40 years: impact of climatic and human factors. J Am Mosq Control Assoc 14:121-130

Nicholson S (2005) On the question of the "recovery" of the rains in the West African Sahel. J Arid Environ 63:615-641

Noor AM, Mutheu JJ, Tatem AJ, Hay SI, Snow RW (2009) Insecticide-treated net coverage in Africa: mapping progress in 2000-07. Lancet 373:58-67

Omumbo JA, Lyon B, Waweru SM, Connor SJ, Thomson MC (2011) Raised temperatures over the Kericho tea estates: revisiting the climate in the East African highlands malaria debate. Mala $\mathbf{J}$ 10:12

Paeth H, Born K, Girmes R, Podzun R, Jacob D (2009) Regional climate change in Tropical and Northern Africa due to greenhouse forcing and land use changes. J Clim 22:114-132

Paeth H, Hall NMJ, Gaertner MA, Alonso MD, Moumouni S, Polcher J, Ruti PM, Fink AH, Gosset M, Lebel T, Gaye AT, Rowell DP, Moufouma-Okia W, Jacob D, Rockel B, Giorgi F, Rummukainen M (2011) Progress in regional downscaling of west African precipitation. Atmos Sci Lett 12:75-82. doi:10.1002/asl.306

Pascual M, Cazelles B, Bouma MJ, Chaves LF, Koelle K (2008) Shifting patterns: malaria dynamics and rainfall variability in an African highland. Proc R Soc Lond Ser B 275:123-132

Patz JA, Hulme M, Rosenzweig C, Mitchell TD, Goldberg RA, Githeko AK, Lele S, McMichael AJ, le Sueur D (2002) Regional warming and malaria resurgence. Nature 420:627-628

Peterson AT (2009) Shifting suitability for malaria vectors across Africa with warming climates. BMC Infect Dis 9:59. doi:10.1186/1471-2334-9-59

Reiter P (2001) Climate change and mosquito-borne disease. Environ Health Perspect 109:141-161

Reiter P, Thomas CJ, Atkinson PM, Hay SI, Randolph SE, Rogers DJ, Shanks GD, Snow RW, Spielman A (2004) Global warming and malaria: a call for accuracy. Lancet Infect Dis 4:323-324

Rogers DJ, Randolph SE (2000) The global spread of malaria in a future, warmer world. Science 289:1763-1766 (Corrected in print, 29 Sept 2000, p 2283)

Rogers DJ, Randolph SE (2006) Climate change and vector-borne diseases. Adv Parasitol 62:345381

Snow RW, Guerra CA, Mutheu JJ, Hay SI (2008) International funding for malaria control in relation to populations at risk of stable Plasmodium falciparum transmission. PLoS Med 5:e142

Tanser FC, Sharp B, le Sueur D (2003) Potential effect of climate change on malaria transmission in Africa. Lancet 362:1792-1798

Thomas CJ, Davies G, Dunn CE (2004) Mixed picture for changes in stable malaria distribution with future climate in Africa. Trends Parasitol 20:216-220

van Lieshout M, Kovats RS, Livermore MTJ, Martens P (2004) Climate change and malaria: analysis of the SRES climate and socio-economic scenarios. Glob Environ Change 14:87-99

World Health Organization (2008) Global malaria control and elimination: report of a technical review. Tech. rep., WHO, Geneva, Switzerland, http://whqlibdoc.who.int/publications/2008/ 9789241596756_eng.pdf. Accessed 2 Dec 2010 